\title{
Academic journal indexes and metrics: What are they?
}

\section{Rajak A ${ }^{1}$ D四, Bajracharya A ${ }^{2}$ iD}

${ }^{1}$ Ashik Rajak, Editorial Assistant, Journal of Kathmandu Medical College, Kathmandu, Nepal; ${ }^{2}$ Aliza Bajracharya, Alka Hospital, Lalitpur, Nepal

6 T s the journal you work for PubMed indexed?', 'Are we submitting our paper to an indexed journal?' 'What is the journals impact factor?' are among a few questions we as researchers and editor of a medical journal come across every once in a while. Answering the question in a word is quite simple, but the curiosity that follows right after and the confusion that arises on failing to accurately understand what is being said misleads quite a lot of authors, especially authors who are embarking on their journey in the field of medical research. Having a general idea of what 'indexing' is, how it works and why is it important is vital as we march into this ever growing field.

Put simply, an 'index' is a list of items pulled together for a purpose. Likewise, journal indexes (also called bibliographic indexes or bibliographic databases) are lists of journals, organized by discipline, subject, or type of publication'. Even more concisely, an 'indexed journal' is one that has its issues included in a database. And yes, one specific journal can be indexed in a number of databases.

So that gives an idea why the 'indexed' journals are very attractive to authors and to readers. 'Indexation' to authors represent recognition, credibility, authenticity in terms of its originality and accessibility to a wide group

\section{Access this article online}

Website: www.jkmc.com.np

DOI: https://doi.org/10.3126/jkmc.v9i4.38089

HOW TO CITE

Rajak A, Bajracharya A. Academic journal indexes and metrics: What are they? J Kathmandu Med Coll. 2020;9(4):177-181.

Address for correspondence

\section{Dr. Ashik Rajak}

Editorial Assistant, Journal of Kathmandu Medical College, Kathmandu Medical College Teaching Hospital

P.O. Box number: 21266, Sinamangal, Kathmandu, Nepal

E-mail: ashikrj7@gmail.com

Copyright @ 2020 Journal of Kathmandu Medical College (JKMC)

ISSN: 2019-1785 (Print), 2091-1793 (Online)

(i) (5) This work is licensed under a Creative Commons Attribution-Non Commercial 4.0 International License. of researchers promoting readership. The number of open access scholarly journals have increased rapidly in the recent times. This has led to scholarly literature being free of charge and the application of the open license for copyright has removed all barriers to copying or reuse - reduced or removed, thus making the conventional or non-open access journals less likely to be read and inaccessible to many authors in a country like ours. Having said that, indexed journals will have a higher reputation with a good peer review process, recognized peer reviewers - leading to high quality content and updated information in a particular field compared to unindexed ones or ones indexed in only a few indexes.

As much as the indexes are valued, it is quite interesting to realize how each of these came about, evolving from the traditional paper based index to become entirely digitalized in the modern era. Now, we proceed to learning more about a few well known indexes / databases, the metrics used and what they represent.

\section{DIFFERENT JOURNAL INDEXES AND METRICS}

\section{PubMed/ MEDLINE / PMC}

These three terms are often seen to be used synonymously but there exists a difference between them. With over 32 million references, PubMed is an indexing service available since 1996 for journals in the medical profession, including the MEDLINE database.

MEDLINE which can be considered the largest subset of PubMed, is the National Library of Medicine (NLM) journal citation database which was started in the $1960 \mathrm{~s}^{2}$. To index citations, MEDLINE uses the NLM controlled vocabulary, Medical Subject Headings (MeSH), which sets MEDLINE apart from PubMed and can help limit PubMed search retrieval to MEDLINE citations. An article can appear in PubMed but not be "indexed" in MEDLINE".

On the other hand, PMC (PubMed Central) is a free archive for full-text biomedical and life sciences journal articles launched in 2000. PMC serves as a digital counterpart to the NLM extensive print journal collection; is a repository for journal literature deposited by participating 
publishers, as well as for author manuscripts that have been submitted in compliance with the NIH Public Access Policy and similar policies of other research funding agencies. Some PMC journals are also MEDLINE journals ${ }^{4}$.

Almost all PubMed content (91\%) is indexed in MEDLINE; however, since the launch of PMC, the percentage of PubMed records indexed in MEDLINE has slowly decreased $^{5}$.

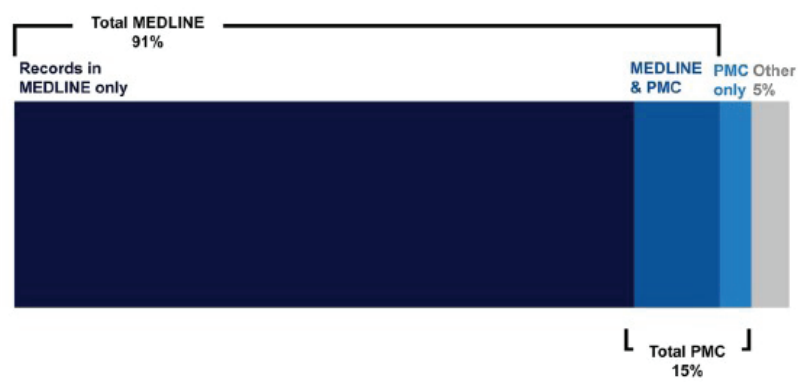

Figure 1: Composition of PubMed in $2017^{5}$

Being around since 1879, Index Medicus was the most comprehensive index of medical scientific journal articles. Subsequently over the years, NLM created MEDLARS, a bibliographic database, which became MEDLINE (MEDLARS online) in 1971 when the NLM offered MEDLARS searches "online" to other medical libraries, and remote access to the NLM MEDLARS system ${ }^{3}$.

\section{EMBASE (EXCERPTA MEDICA DATABASE - ELSEVIER)}

EMBASE is a biomedical and pharmacological bibliographic database produced by Elsevier, containing over 32 million records from 1947 onwards.

Vaguely understood Impact factor (IF) is considered to be an essential tool for investigating the level of influence and impact that a journal has had on the international research community. It is important to note that all journals do not have an IF and the IF is updated every year. In addition, IF does not measure the quality of an article but rather that of the journal in which the article is published.

\section{SCIENCE CITATION INDEX EXPANDED (SCIE) - WEB OF SCIENCE}

Often misunderstood, the term 'impact factor' comes up striking in between conversations. To understand what it is, we go back slightly in time to understand what JCR is.
Journal Citation Reports (JCR) began as a publication of Clarivate Analytics (previously known as the Institute for Scientific Information (ISI)) in 1975 as part of the Science Citation Index $(\mathrm{SCl})$ and the Social Sciences Citation Index $(\mathrm{SSCl})^{6}$. The famous 'impact factor' invented in the '60s is a scientometric metric used by JCR and is annually calculated.

Impact factor (IF) or journal impact factor (JIF)

Yearly average number of citations articles published in the last two years in a given journal received $^{6}$

JCR can be accessed online via the Web of Science platform (WOS) - https://mjl.clarivate.com/ home and is known to include publications reviewed by the most widely-cited experts in the world.

\section{SCOPUS (ELSEVIER)}

Primarily known for its prominent domain experts and peers, Scopus is a bibliographic database run by Elsevier covering many disciplines. The Scopus Journal Analyzer provides a view of journal performance, by ranking them using three journal metrics - SJR (SCImago Journal \& Country Rank), CiteScore and SNIP (Source Normalized Impact per Paper) ${ }^{7}$.

\section{SCIMAGO JOURNAL AND COUNTRY RANK (SJR)}

SJR is specific to publications indexed in Scopus, and became known as a free substitute to the JCR. Including a greater number of articles compared to JCR, SJR permits readers to explore using the Scopus platform, which is a paid-for tool ${ }^{8}$.

Details the number of links that a journal
receives based on the weighted citation
of its documents relative to the number of
documents published in that year by each
publication.
The citation period is three years (a year
longer compared to JCR) and it can be
calculated on a yearly basis from 1999.
The calculation disregards citations to
documents published within the journal
itself ${ }^{8}$.
Is similar to the IF but is based on a 4-year
period

SJR measures the quality of a journal rather than the quality of the article and the impact index of a journal title in any given year may vary and is not a fixed index in SJR. 
Eigenfactor scores are intended to give a measure of how likely a journal is to be used, and are thought to reflect how frequently an average researcher would access content from that journal ${ }^{9}$.

\section{QUARTILES}

In addition to the Impact Factor or Impact Index, rankings of journals in each subject category are divided into quartiles by both JCR and SJR ${ }^{7}$. The journals is each subject group are divided and ranked into quartiles Q1, Q2, Q3 and Q4 where journals occupying the first quartile, Q1 are the most prestigious ones with the highest impact factor or impact index.

\begin{tabular}{|cl}
\hline Quartile & \\
Q1 & occupied by the top $25 \%$ of journals in the list \\
Q2 & occupied by journals in the 25 to $50 \%$ group \\
Q3 & occupied by journals in the 50 to $75 \%$ group \\
Q4 & occupied by journals in the 75 to $100 \%$ group \\
\hline
\end{tabular}

\section{DIFFERENCES BETWEEN JCR AND SJR}

While being used extensively, it is also important to note the differences between the SJR and JCR.

$\begin{array}{ll} & \text { JCR is a paid-for tool which is accessed } \\ \text { via the Web Of Science platform whereas } & \text { SJR is free of charge despite the fact } \\ \text { that the database of citations on which } \\ \text { it is supported - Scopus - is a paid-for } \\ \text { service. } \\ \text { In JCR, the citation period covers two } \\ \text { years and every citation has the same } \\ \text { Citation data } & \begin{array}{l}\text { weightage and same value whereas in SJR } \\ \text { the citation period covers three years and }\end{array} \\ \text { collected for } & \text { the citations are all weighted, meaning } \\ \text { indicators } & \begin{array}{l}\text { that the value of the citation depends on } \\ \text { the position occupied by the journal in } \\ \text { which the citations are made. }\end{array}\end{array}$

\section{GOOGLE SCHOLAR}

To evaluate the journals on Google scholar, the concept of Google scholar metrics was developed which include the $\mathrm{h} 5$-index and $\mathrm{h} 5$-median index. These indices calculate the citations received in the five complete calendar years prior to the realization of the metric. Using data based on the $h$-index, Google Scholar provides the h5- or in5index of publications.

$\begin{array}{ll} & \text { The main indicator adopted and it is } \\ \text { the } h \text {-index for articles published in the } \\ \text { h5-index } & \begin{array}{l}\text { last } 5 \text { complete years. It is the largest } \\ \text { number h such that } h \text { articles published } \\ \text { in } 5 \text { years have at least } h \text { citations each. }\end{array} \\ \text { h5-median } & \begin{array}{l}\text { The median number of citations for the } \\ \text { articles that make up its h5-index. }\end{array}\end{array}$

Directory of Open Access Journals (DOAJ) is a community-curated online directory that indexes and provides access to high quality, open access, peerreviewed journals and data free of charge. It can be accessed at https://doaj.org.

Index Copernicus International (ICI) World of Journals is a global database dedicated to ensuring that scientific journals are using transparent editorial practices around the world.

EBSCO is a full-text coverage database of scholarly journals, magazines, and articles.

Index Medicus for South-East Asia Region (IMSEAR) archives selected publications in health sciences in the WHO South-East Asia Region.

With the aim to provide a common platform for 'repository' and 'indexing' of all Nepalese biomedical journals, Nepal MEDLINE (Medical Literature Analysis and Retrieval System Online) - also known as NepMed was launched in 2019. Another service - Nepal Journals Online (NepJol), initially established by INASP in 2007 and currently managed by Tribhuvan University Central Library has become popular, enhancing visibility of participating journals, and the research they convey.

With the growing number of researches and publication, publishers needed an efficient method to connect journal articles which led to Crossref in 2000 as a way to link references between articles, making it easier for a reader to locate items that are cited using the Digital Object Identifier (DOI). With organizations like the International Committee of Medical Journal Editors, Committee on Publication Ethics (COPE), World Association of Medical Editors (WAME) and Open Access Scholarly Publishing Association (OASPA) working in the field of research globally with their own missions in scientific, technical, ethical and scholarly disciplines, the field of research continues to grow extensively.

Having gathered some insight regarding the fundamentals of different indexes, selecting a high quality journal might still not be so straightforward.

It is firstly important to make sure that a journal you want to submit a manuscript to is within the scope of your article, after which you might then prioritize and pick one, always abiding by publication ethics. Before proceeding, it is always wise to check if the journal is actually indexed in the database it claims to be indexed in. This will prevent authors from being a victim of some 
'predatory journal or publisher' out there. For instance, the NLM Catalog helps to confirm if a journal is indexed in Index Medicus, MEDLINE or PubMed. Other indexes can accessed via the respective index's website.

With a number of indexation services coming up with time, it is unclear as to which indexation in the best and most valid and if all of those are equally reliable. While still being used universally, IF is not available for all indexed journals and in fact, not all journals indexed even in Index Medicus / MEDLINE / PubMed are indexed in the Thomson Reuters Journal Citation Reports and vice-versa ${ }^{10}$. Furthermore, the implication of IF itself, is at times controversial as there are multiple factors that could bias the calculation of the IF including procedures used to collect citations, citation distribution of journals, online availability of publications, negative citations and the algorithm itself ${ }^{11,12}$. IF has been used as a proxy for the relative importance of a journal within its field and in the past, subjected to criticism for manipulation and incorrect application ${ }^{13}$. All these cause the IF's to mean little on their own.

Some authors are misled to understanding that Research Gate and Publons are indexes but in fact are not. They are platforms that allow networking, showcasing ones work and tracking citations. In addition, Springer, Wiley, PLOS, Elsevier etc. are publishers and not indexes. Moreover, it might not be true that any article that ends up appearing in a search in a search engine is actually indexed.

Different indexes have their own criteria for eligibility to include journals in their indexes. Many qualitative and quantitative factors are taken into account when evaluating journals for coverage including basic publishing standards, editorial content, international focus, citation analysis, to name a few.

\section{REFERENCES}

1. Walden University. Library Guide to Academic Publishing: Journal Indexes [Internet]. 2021. [Full Text]

2. Manca A, Moher D, Cugusi L, Dvir Z, Deriu F. How predatory journals leak into PubMed. CMAJ. 2018;190(35):E1042-E1045. [PubMed | DOI]

3. National Library of Medicine. MEDLINE, PubMed, and PMC (PubMed Central): How are they different? [Internet]. Bethesda: 2021. [PubMed]

4. Library Resources: Health Services Administration [Internet]. Xavier University. 2021. [Full Text]
Monitoring the novelty of a paper, quality of content and facilitating the review process is of prime importance, both by the journal and the indexes. Accompanied with the reputation of being 'indexed' comes a lot of responsibilities on the shoulders of the editors and the editorial board. What might always stay behind the curtain are the efforts of the editors trying to control quality to keep up with the practices and standards of indexes at all times; which some authors fail to realize, as they run their own races for publication. Many might neglect the fact that indexes also monitor the quality of the content of the journals and articles within their index every now and then, even leading to de-indexation at times, as done by Scopus recently.

While indexation is often considered to reflect the quality of a journal, it has also become debatable at instances. At times we need to make a decision regarding submitting a manuscript to a PubMed indexed journal or one with a high impact factor that is not indexed with PubMed, which might really turn confusing. At such instances, it would be best to view the journal you are interested, in comparison to the other journals in the same index itself. To clearly mark the lines between different indexes, organizations including the International Committee of Medical Journal Editors will have a major role in the future ${ }^{14}$.

Except a few instances where journal editors have abused the scientific or scholarly processes by publishing low quality research by commercializing journals to ensure fast publication against the journals policies, we can agree that indexed journals are definitely a better venue for high quality publication and stands a higher ground compared to ones that are not indexed.

\section{Conflict of interest: None}

5. Ossom PW, Minter CIJ. Exploring PubMed as a reliable resource for scholarly communications services. J Med Libr Assoc. 2019;107(1):16-29. [PubMed |DOI]

6. The Clarivate Analytics Impact Factor [Internet]. Clarivate. 2021. [Full Text]

7. Journal Impact Factors [Internet]. University of Exeter. 2021. [Full Text]

8. Mondragon Unibertsitatea. Publications Impact Indexes [Internet]. 2017. [Full Text]

9. Publishing Your Research in the Humanities and Social Sciences: Journal Selection: Databases [Internet]. University of Wisconsin-Madison Libraries. 2021. [Full Text] 
10. Kapoor S, Sikka P, Saxena K. Publication of research article: an art or science? Ann Med Health Sci Res. 2013 Jan;3(1):96-8. [PubMed | DOI]

11. Malathi M, Thappa DM. The intricacies of impact factor and mid-term review of editorship. Indian J Dermatol Venereol Leprol. 2012;78:1-4. [PubMed | DOI]
12. Balhara YP. Publication: An essential step in research. Lung India. 2011;28:324-5. [PubMed | DOI]

13. Not-so-deep impact. Nature. 2005;435(7045):1003-4. [DOI]

14. Balhara YP. Indexed journal: What does it mean? Lung India. 2012;29(2):193. [PubMed | DOI] 